OPEN ACCESS

Edited by:

Kerrie Leanne McDonald,

University of

New South Wales, Australia

Reviewed by:

Justin Lathia,

Cleveland Clinic Lerner

College of Medicine, USA

Eric Hau,

St George Hospital, Australia

*Correspondence:

Jing $\mathrm{Li}$

jing.li@mdanderson.org

Specialty section:

This article was submitted to

Neuro-Oncology,

a section of the journal

Frontiers in Oncology

Received: 02 August 2016 Accepted: 26 September 2016

Published: 07 October 2016

Citation:

D'Souza NM, Fang P, Logan J,

Yang J, Jiang $W$ and $L i J$

(2016) Combining Radiation

Therapy with Immune

Checkpoint Blockade for Central Nervous System Malignancies.

Front. Oncol. 6:212.

doi: 10.3389/fonc.2016.00212

\section{Combining Radiation Therapy with Immune Checkpoint Blockade for Central Nervous System Malignancies}

\author{
Neil M. D’Souza',2, Penny Fang ${ }^{1}$, Jennifer Logan', Jinzhong Yang ${ }^{1}$, Wen Jiang ${ }^{1}$ and Jing Li $^{1 *}$ \\ ${ }^{1}$ Department of Radiation Oncology, The University of Texas MD Anderson Cancer Center, Houston, TX, USA, ${ }^{2}$ Baylor \\ College of Medicine, Houston, TX, USA
}

Malignancies of the central nervous system (CNS), particularly glioblastoma and brain metastases from a variety of disease sites, are difficult to treat despite advances in multimodality approaches consisting of surgery, chemotherapy, and radiation therapy (RT). Recent successes of immunotherapeutic strategies including immune checkpoint blockade (ICB) via anti-PD-1 and anti-CTLA-4 antibodies against aggressive cancers, such as melanoma, non-small cell lung cancer, and renal cell carcinoma, have presented an exciting opportunity to translate these strategies for CNS malignancies. Moreover, via both localized cytotoxicity and systemic proinflammatory effects, the role of RT in enhancing antitumor immune response and, therefore, promoting tumor control is being re-examined, with several preclinical and clinical studies demonstrating potential synergistic effect of RT with ICB in the treatment of primary and metastatic CNS tumors. In this review, we highlight the preclinical evidence supporting the immunomodulatory effect of $\mathrm{RT}$ and discuss the rationales for its combination with ICB to promote antitumor immune response. We then outline the current clinical experience of combining RT with ICB in the treatment of multiple primary and metastatic brain tumors. Finally, we review advances in characterizing and modifying tumor radioimmunotherapy responses using biomarkers and microRNA (miRNA) that may potentially be used to guide clinical decision-making in the near future.

Keywords: immune checkpoint blockade, immunotherapy, radiotherapy, CTLA-4, PD-1, glioblastoma, brain metastases, brain neoplasms

\section{INTRODUCTION}

Recent advances in the field of tumor immunology, such as the discovery of monoclonal antibodies targeting immune checkpoints, have opened a new frontier in the fight against cancer. These monoclonal antibodies recognize and inhibit immune suppressive functions mediated by cytotoxic T-lymphocyte associated protein 4 (CTLA-4) and programmed cell death protein 1 (PD-1) receptors to promote immune-mediated antitumor activity (1-5). In the setting of metastatic melanoma, non-small cell lung cancer (NSCLC), Hodgkin's lymphoma, and renal cell carcinoma (RCC), these agents achieved significant improvement in clinical responses and survival as monotherapies, but only in limited subsets of patients $(1,6-8)$. In order to broaden clinical utility and efficacy, recent investigations have focused on combination schemes that provide immune activation, 
while counteracting inhibitory checkpoint signals. Radiation therapy (RT) has traditionally been perceived to be a local treatment strategy with potentially immunosuppressive effects $(1,9)$. However, recent data suggests that RT can trigger the "abscopal effect," which describes treatment response in tumors outside the radiation fields through systemic immune-mediated antitumor effects $(1,10-14)$. Other types of immunostimulatory effects of RT have been observed in preclinical studies, and recent clinical studies exploring the role of RT in combination with immunotherapy have shown synergism between these two treatment modalities (15-17).

The brain has traditionally been considered an immunoprivileged entity with most systemic therapies demonstrating minimal to no intracranial activity. While recent advances in systemic therapy have significantly improved patient outcomes including survival, treatment of brain metastasis continues to represent a unique challenge, particularly for patients with neurotropic primaries, such as melanoma, NSCLC, and breast cancer (18). Similar challenges exist in the treatment of primary central nervous system (CNS) malignancies, such as glioblastoma, which is highly invasive and carries a 5-year survival rate of less than $10 \%$ $(19,20)$.

Fortunately, recent data have suggested that the CNS does indeed interact with the immune system and is subject to a dynamic regulation via proinflammatory and immunosuppressive forces (21-23). With the development of immune checkpoint blockade (ICB), studies investigating combination therapy of ICB with traditional standard treatment, including RT, have suggested potential synergistic effects in the brain (24-27). In this review, we provide an overview of the immune modulatory effect of RT and rationales for radioimmunotherapy using ICB. We also aim to explore the future outlook of this emerging paradigm as well as the development of new biomarker platforms that can help harness the full potential of this combined approach in the treatment of CNS malignancies.

\section{PRECLINICAL RATIONALES}

\section{Immunostimulatory and Systemic Antitumor Effects of Radiation Therapy}

Although radiation has traditionally been considered an immunologically inert process, the recent discovery of immunogenic cell death (ICD), a unique mode of cell death induced by RT or chemotherapy via potent host-mediated antitumor response (28), has suggested otherwise. Cell death occurs differently depending on the identity and maturity of the phagocytic cell, location and manner of phagocytosis, the availability of helper T-lymphocytes, type of death pathway that is triggered, release of immunosuppressive mediators (TGF- $\beta$, IL-10), and the immune cells that are exposed to antigens (29). ICD in particular is primarily defined by unique molecular processes, including the translocation of calreticulin (CRT) to the cell surface, ATP release, upregulation of costimulatory molecules, and the extracellular release of high-mobility group protein B1 (HMG-B1), which enhances antigen cross-presentation and secretion of proinflammatory cytokines $(28,30)$.
Although RT has been speculated to exert immunosuppressive effects via increased TGF-beta expression, M2 macrophage polarization, and T-regulatory (T-reg) cell recruitment, its immunostimulatory effect is beginning to be understood (31-34). Ionizing radiation has been shown to increase translocation and expression of CRT (35) and promote gene transcription of proinflammatory factors via HMG-B1 (36, 37 ), which are the essential components of ICD, as well as reduce production of immune suppressive cytokines and increase expression of MHC-I and synthesis of novel peptides for cytotoxic T cell recognition (38). Moreover, RT has been shown to promote re-oxygenation and decrease interstitial fluid pressure within the tumor microenvironment, improving immune cell recruitment and infiltration into irradiated tumor (39). Finally, RT induces the release of tumor-associated antigens (TAAs), diversifying the TCR (T-cell receptor) repertoire of infiltrating CTLs and leading to increased efficacy of CTLs $(27,40)$. Notably, these cancer-specific and stromal-associated responses occur simultaneously and define radiation-induced immunogenicity of the tumor cells. Preclinical studies have clearly suggested that radiation, although conventionally perceived as a local therapy, can potentially exert systemic antitumor effects at least through both cancer cell intrinsic and tumor microenvironmental modulations. These mechanisms are illustrated in Figure 1.

\section{Immune Checkpoint Blockade and CNS Tumors}

While the brain has traditionally been considered an immunoprivileged organ system, it is now commonly accepted that dysregulation of immune surveillance may be involved in the pathogenesis and progression of multiple CNS malignancies (41). Similar to other types of cancers, primary brain tumors can evade immune system detection through multiple immunosuppressive mechanisms, including upregulation of immune checkpoints. For example, $\mathrm{PD}$-L1 has been shown to be upregulated in glioblastoma cells as well as circulating monocytes and macrophages through oncogenic signaling resulting from PTEN loss and modulation of autocrine-paracrine IL-10 signaling (42-44). Increased PD-1 and PD-L1 expression has also been observed in brain metastases and primary CNS lymphomas $(45,46)$. These findings warrant further exploration of ICB, in particular PD-1 or PD-L1 blockers, in the pathogenesis and treatment of primary and metastatic CNS malignancies.

Radiation therapy is the pillar of standard therapy for primary and secondary brain tumors. The immunostimulatory effects of RT make it a natural candidate as a synergistic partner with ICB. Indeed, prior preclinical studies have shown survival benefits of radiation with tumor vaccination in glioma mice models (20). In melanoma, RT has been shown to diversify TCR repertoire of infiltrating CTLs and enhance their function via RT-induced release of TAAs (27). This mechanism worked in concert with an anti-CTLA-4 agent leading to inhibition of T-reg cell function and increased $\mathrm{CD} 8^{+} \mathrm{T}$ cell/T-reg ratio. Interestingly, the addition of an anti-PD-L1 agent further prevented T cell exhaustion (40). In murine glioma models, combining radiation concurrently 


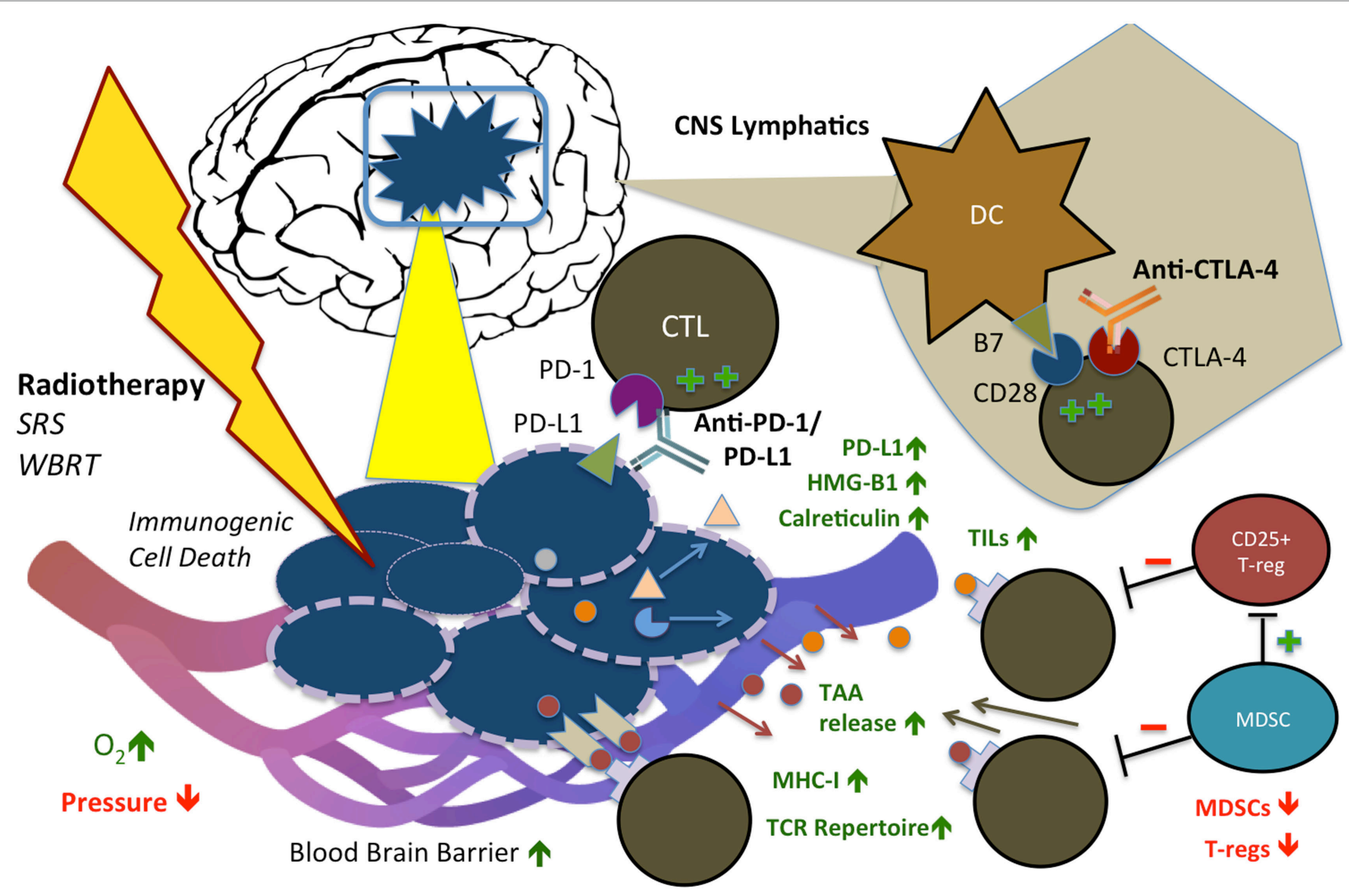

\section{Tumor Microenvironment}

FIGURE 1 | Immunostimulatory effects of radiation therapy (RT) in combination with immune checkpoint blockade (ICB) in the CNS. RT and ICB work synergistically to create an immunogenic tumor microenvironment and promote systemic antitumor response. Anti-PD-1 and PD-L1 agents reduce tumor cell-mediated exhaustion signals to CD8 ${ }^{+}$CTLs, while anti-CTLA-4 agents block competing co-inhibitory activity of CTLA-4, resulting in increased and persistent T-cell activation. RT triggers immunogenic cell death (ICD) of tumor cells, displacement of calreticulin (CRT) to the cell surface, release of HMG-B1, increased MHC-I expression, and release of tumor-associated antigens (TAAs), with consequent increase in TCR repertoire of infiltrating T-cells. In addition, RT has stromal effects on the tumor microenvironment: increasing oxygenation, infiltration of TILs, and permeability of the blood-brain barrier (BBB), while decreasing interstitial fluid pressure. In combination with ICB, RT also reduces activity of T-regs and MDSCs. SRS, stereotactic radiosurgery; WBRT, whole brain radiation therapy; CTL, cytotoxic T-lymphocyte; PD-1/L1, programmed cell death protein 1/ligand 1; CTLA-4, cytotoxic T-lymphocyte-associated protein 4; DC, dendritic cell; TIL, tumor-infiltrating Iymphocyte; TAA, tumor-associated antigen; MHC, major histocompatibility complex; TCR, T-cell receptor; MDSC, myeloid-derived suppressor cell; HMG-B1, high mobility group box 1 .

with anti-PD-1 and anti-CTLA-4 or 4-1BB (a costimulatory molecule) agonist yielded improved survival and increased tumor-infiltrating leukocyte (TIL) population, compared with either modality alone $(24,47)$. The rationale for combining RT with PD-1/PD-L1 blockers is further supported by the observation that local inflammation mediated by RT results in PD-L1 upregulation on cancer cells, macrophages, and dendritic cells (DCs) (48). Moreover, a recent study in murine melanoma brain metastases (MBM) showed that increasing radiation dose with concurrent immunotherapy improved median and long-term survival and prolonged tumor dormancy (49). Finally, while the penetrance of ICB agents into the CNS via the blood-brain barrier (BBB) is not fully known, RT has been shown to increase BBB permeability (50), further facilitating the penetrance of activated antitumor immune cells and possibly the access of ICB agents as well - providing another compelling rationale for combination RT-ICB therapy in the treatment of primary and metastatic CNS tumors (Figure 1).

\section{CLINICAL STUDIES AND EXPERIENCE}

The combination of RT and ICB has been reported to improve clinical outcomes in multiple metastatic cancers. In metastatic melanoma, potential radiation-induced abscopal responses have been reported in the setting of CTLA- 4 blockade $(10,51,52)$. The first of such reports was by Postow et al., who described a patient with paraspinal, splenic, and right hilar metastatic disease receiving palliative radiation to the paraspinal lesion with concurrent ipilimumab. Five months after treatment, all lesions demonstrated regression on restaging CT scans (10). Similar case studies have 
reported potential clinical benefits of combining radiation with ICB in metastatic melanoma $(51,52)$ as well as NSCLC (53).

In addition to immunogenic tumors, such as melanoma and NSCLC, the role of radiation combined with ICB has also been investigated in metastatic, castration-resistant prostate cancer. A recently completed phase I/II trial looked at combining ipilimumab and palliative RT to bony disease and found a complete response rate of $2 \%$ and stable disease in $12 \%$ of patients (54). Although no difference in overall survival was noted, there were signs of enhanced antitumor activities in the ipilimumab arm with decreased PSA and improved progression-free survival (PFS). It is, however, questionable, whether radiation contributed to these benefits as both the ipilimumab and placebo arms received RT. Another early trial attempted to ask this question by looking at ipilimumab vs. ipilimumab plus RT in metastatic prostate cancer and demonstrated promising clinical response (55). However, a phase III trial of this regimen in men with previously treated CRPC failed to demonstrate a significant overall survival benefit (56).

In the metastatic disease setting, there are multiple ongoing trials combining RT, particularly stereotactic radiosurgery (SRS) or hypofractionated radiation, with immunotherapy in multiple cancer types. At MD Anderson, we are currently investigating different combinations of immune checkpoint blockers with stereotactic body radiation therapy (SBRT) for lung and liver metastasis from multiple primary sites (NCT02239900, NCT02402920, NCT02444741).

\section{Brain Metastases}

Clinical evidence supporting the efficacy of combining RT and ICB in the treatment of CNS tumors is primarily garnered from melanoma patients with metastatic disease and is retrospective in nature. Three retrospective single-institution studies have suggested that ipilimumab in combination with RT may be more effective than RT alone in MBM (57-60). Knisely et al. reviewed the outcomes of 77 patients with MBM who received SRS as well as ipilimumab. Patients who received combination therapy demonstrated improved survival compared with those who received SRS alone (58). Moreover, a study by Silk et al. explored the benefits of combination therapy vs. RT alone in $70 \mathrm{MBM}$ patients who received brain radiation (either SRS or WBRT) with ipilimumab. Retrospective analysis demonstrated an OS benefit of 19.9 months with combination therapy vs. 4.0 months for SRS alone, with no associated increase in toxicity with addition of ipilimumab to SRS (59). An interesting study by Kiess et al. investigated the impact of timing in administration of SRS for brain metastases and ICB on patient outcome. Patients who received SRS before or concurrently with ipilimumab appeared to exhibit improved outcomes in OS and distant intracranial control compared to patients who received radiation after immunotherapy (60). Notably, responses to ipilimumab therapy in the brain, as in extracranial disease, can be quite durable with some reported response beyond 4 years (61). Given the retrospective and single institutional nature of these studies, caution needs to be taken regarding interpretation of their results. Several prospective early phase clinical trials at multiple institutions are investigating different combination regimens of RT with immune checkpoint blockers in the setting of brain metastases (Table 1). Results from these studies will one day shed light on the clinical benefit of combining radiation with immunotherapy for the treatment of brain metastases.

\section{Primary Brain Tumors and Ongoing Clinical Trials}

For primary CNS tumors, such as glioblastoma, several combination approaches with radiation have been explored clinically (62). For example, immunotherapy in the form of vaccines derived from autologous DCs and pulsed with tumor lysate and various tumor antigens (such as the EGFRvIII vaccine Rindopepimut) have shown some promise in the clinical setting (20). A randomized phase II trial testing ICT-107, a vaccine composed of autologous DCs and tumor antigens, administered with radiation and temozolomide for newly diagnosed glioblastoma, demonstrated benefit in terms of OS and PFS for a subset of HLA-A2 positive patients (63).

Although evidence supporting the combination of ICB and RT for glioblastoma is currently lacking, several clinical trials are underway examining this combination for newly diagnosed and recurrent glioblastoma (Table 1). Two of these are large multi-institutional trials in phases II and III (NCT02667587, NCT02617589) examining OS in patients given nivolumab in combination with radiation (with/without concurrent temozolomide) for newly diagnosed glioblastoma, while another smaller trial is examining similar combinations with pembrolizumab (NCT02530502). A phase II trial sponsored by the Ludwig Institute is investigating OS in monotherapy with the PD-1 inhibitor durvalumab (MEDI4736) in comparison to combination approaches with standard RT or the VEGF inhibitor bevacizumab. Finally, a phase I trial is examining maximum dosage of pembrolizumab when it is used with combination therapy with bevacizumab and a hypofractionated radiation regimen given over 5 days for recurrent glioma. Additional clinical trials investigating combination approaches in the context of primary CNS malignancy will soon be underway.

\section{Future Outlook}

Glioblastoma is notorious for employing a wide variety of immunosuppressive strategies to disrupt the function of immune cells, lower immunoglobulin levels, and generate a plethora of immunosuppressive processes, involving TGF-beta, IL-10, MHC-I downregulation, T-regs recruitment, and increased expression of PD-L1 (20, 64-68). Development of therapeutics for glioblastoma is complicated by the variability in antigen expression within individual tumors and subtypes. The ability to target the unique signature of tumor-specific mutations and antigens ("neoantigens") is crucial in effective tumor control, and the expression of these neoantigens has been shown to predict long-term response to ICB in metastatic melanoma and NSCLC $(69,70)$. Strategies such as biomarker and microRNA (miRNA) development are under investigation to predict and modulate tumor response to immunotherapy and RT.

\section{Biomarker Identification}

Along with clinical trials, current translational research efforts are exploring potential predictive biomarkers for response to 
TABLE 1 | Current clinical trials of immunotherapy with radiation for primary and metastatic CNS malignancy.

\begin{tabular}{|c|c|c|c|c|c|c|c|c|}
\hline $\begin{array}{l}\text { Study } \\
\text { phase }\end{array}$ & $\begin{array}{l}\text { Institution/ } \\
\text { group }\end{array}$ & $\begin{array}{l}\text { ClinicalTrials. } \\
\text { gov ID }\end{array}$ & Disease site & Cohorts & $\begin{array}{l}\text { Planned } \\
\text { accrual }\end{array}$ & IT mechanism & $\begin{array}{l}\text { Est. } \\
\text { completion } \\
\text { date }\end{array}$ & $\begin{array}{l}\text { Primary } \\
\text { outcome } \\
\text { measure }\end{array}$ \\
\hline$\|$ & $\begin{array}{l}\text { Multi-institutional } \\
\text { (CheckMate548) }\end{array}$ & NCT02667587 & $\begin{array}{l}\text { Newly diagnosed } \\
\text { glioblastoma }\end{array}$ & $\begin{array}{l}\text { Nivolumab + temozolomide + } \\
\text { RT vs. placebo + temozolomide } \\
+ \text { RT }\end{array}$ & $n=320$ & anti-PD-1 & May 2017 & OS \\
\hline III & $\begin{array}{l}\text { Multi-institutional } \\
\text { (CheckMate498) }\end{array}$ & NCT02617589 & $\begin{array}{l}\text { Newly diagnosed } \\
\text { glioblastoma }\end{array}$ & $\begin{array}{l}\text { Nivolumab + RT vs. } \\
\text { temozolomide + RT }\end{array}$ & $n=550$ & anti-PD-1 & October 2019 & OS \\
\hline$\|$ & $\begin{array}{l}\text { Ludwig Institute } \\
\text { for Cancer } \\
\text { Research }\end{array}$ & NCT02336165 & $\begin{array}{l}\text { Newly diagnosed, } \\
\text { recurrent } \\
\text { glioblastoma }\end{array}$ & $\begin{array}{l}\text { MEDI4736 vs. MEDI4736 + } \\
\text { standard RT vs. MEDI4736 + } \\
\text { bevacizumab }\end{array}$ & $n=108$ & anti-PD-1 & July 2017 & OS, PFS \\
\hline $1 / I 1$ & $\begin{array}{l}\text { Northwestern } \\
\text { University }\end{array}$ & NCT02530502 & $\begin{array}{l}\text { Newly diagnosed } \\
\text { glioblastoma }\end{array}$ & $\begin{array}{l}\mathrm{RT}+\text { temozolomide }+ \\
\text { pembrolizumab } \rightarrow \text { temozolomide } \\
+ \text { pembrolizumab }\end{array}$ & $n=50$ & anti-PD-1 & March 2018 & $\begin{array}{l}\text { Dosage, } \\
\text { PFS, OS }\end{array}$ \\
\hline । & $\begin{array}{l}\text { H. Lee Moffitt } \\
\text { Cancer Center }\end{array}$ & NCT02313272 & Recurrent glioma & $\begin{array}{l}\text { HFSRT + pembrolizumab + } \\
\text { bevacizumab }\end{array}$ & $n=32$ & anti-PD-1 & June 2017 & Dosage \\
\hline$|/| \mid$ & $\begin{array}{l}\text { MD Anderson } \\
\text { Cancer Center }\end{array}$ & NCT02696993 & NSCLC BM & $\begin{array}{l}\text { Nivolumab + SRS; nivolumab + } \\
\text { WBRT; nivolumab + ipilimumab } \\
\text { + SRS; nivolumab + ipilimumab } \\
\text { + WBRT }\end{array}$ & $n=130$ & $\begin{array}{l}\text { anti-PD-1; } \\
\text { anti-CTLA-4 }\end{array}$ & April 2020 & $\begin{array}{l}\text { Dosage; } \\
\text { PFS }\end{array}$ \\
\hline$\|$ & $\begin{array}{l}\text { Grupo Español } \\
\text { Multidisciplinar de } \\
\text { Melanoma (GEM) }\end{array}$ & NCT02115139 & Melanoma BM & Ipilimumab + WBRT & $n=66$ & anti-CTLA-4 & $\begin{array}{l}\text { October } \\
2016\end{array}$ & $\begin{array}{l}\text { 1-year } \\
\text { survival rate }\end{array}$ \\
\hline$\|$ & $\begin{array}{l}\text { University of } \\
\text { Michigan Cancer } \\
\text { Center }\end{array}$ & NCT02097732 & Melanoma BM & $\begin{array}{l}\text { Ipilimumab } \rightarrow \text { SRS } \rightarrow \text { ipilimumab } \\
\text { vs. SRS } \rightarrow \text { ipilimumab }\end{array}$ & $n=40$ & anti-CTLA-4 & May 2017 & $\begin{array}{l}\text { Local } \\
\text { control rate }\end{array}$ \\
\hline । & $\begin{array}{l}\text { Thomas Jefferson } \\
\text { University }\end{array}$ & NCT01703507 & Melanoma BM & $\begin{array}{l}\text { Ipilimumab + WBRT vs. } \\
\text { ipilimumab + SRS }\end{array}$ & $n=24$ & anti-CTLA-4 & $\begin{array}{l}\text { November } \\
2017\end{array}$ & Dosage \\
\hline । & $\begin{array}{l}\text { Sidney Kimmel } \\
\text { Comprehensive } \\
\text { Cancer Center }\end{array}$ & NCT01950195 & Melanoma BM & Ipilimumab + SRS & $n=30$ & anti-CTLA-4 & $\begin{array}{l}\text { December } \\
2016\end{array}$ & $\begin{array}{l}\text { Adverse } \\
\text { events and } \\
\text { safety }\end{array}$ \\
\hline$\|$ & $\begin{array}{l}\text { University } \\
\text { Hospital, Lille }\end{array}$ & NCT02662725 & Melanoma BM & Ipilimumab + SRS & $n=73$ & anti-CTLA-4 & $\begin{array}{l}\text { December } \\
2015\end{array}$ & OS \\
\hline
\end{tabular}

RT, radiation therapy; PD-1, programmed cell death protein 1; OS overall survival, PFS, progression-free survival; HFSRT, hypofractionated stereotactic radiotherapy; IMRT, intensitymodulated radiation therapy; CTLA-4, cytotoxic T-lymphocyte-associated protein 4; irRC, immune-related response criteria; WBRT, whole brain radiation therapy; NSCLC, non-small cell lung cancer; BM, brain metastases; SRS, stereotactic radiosurgery; MM, metastatic melanoma; SBRT, stereotactic body radiation therapy.

immunotherapies in glioblastoma (71). Increased PD-L1 expression in circulating monocytes has been identified as a biomarker for tumor-induced immunosuppression and a prognostic factor for poor survival. For example, in one study of glioblastoma patients, the median overall survival for high-expressers of PD-L1 was 18.0 months compared with 44.7 months for low PD-L1 peripheral monocyte expressers (5). Another example is level of tumor EGFRvIII expression as a biomarker for response to the EGFRvIII vaccine in glioblastoma (72). Increased peripheral blood levels of $\mathrm{CD}^{3} 3^{+} \mathrm{HLA}-\mathrm{DR}^{-}$myeloid-derived suppressor cells (MDSCs), with the potential to induce T-regs and apoptosis in activated lymphocytes as well as secrete immunosuppressive cytokines and oxidizing molecules, have also been reported patients with glioblastoma. RT in combination with ICB has been shown to reduce tumor-associated MDSCs in comparison to single therapy via the activity of $\mathrm{CD} 8^{+} \mathrm{T}$ cells and tumor necrosis factor (TNF) signaling in vivo (48). Moreover, a diminution in the level of circulating T-regs has shown promise as a biomarker for treatment response to immunotherapies (73).
MicroRNAs can act as oncogenes or tumor suppressors through controlling target gene expression and binding of mRNA, and also carry promise as biomarkers (74). In glioblastoma, tumor miR-21 has been a promising candidate as a biomarker in diagnosis and response to chemotherapies (75). In the serum, levels of miR-128, miR-320, and miR-574-3p have been found to be elevated $(76,77)$. Interestingly, the presence of metastatic disease in the brain can be distinguished from glioblastoma via the identification of the miR-200 family in cerebrospinal fluid (78). miRNA can also serve as targets for therapy. Double-stranded miRNA mimics can reinstate activity of tumor suppressor miRNA, and oncogenic miRNAs can be disenabled by single-stranded antisense nucleotides known as "antimiRs" (79). One example in the CNS is miR-296, which led to reduced tumor volume and angiogenesis in a murine glioma model (80). Another miRNA, miR-221/222, demonstrated reduced tumor volume in murine melanoma (79). A potential target for an miRNA mimic in ICB is miR-138, which has been demonstrated to target both CTLA-4 and PD-1, inhibiting tumor-infiltrating T-regs and 
subsequently releasing the brake set by these immunosuppressive cells within the glioblastoma microenvironment (81). Whether specific miRNA can be used to predict treatment responses to immunotherapy warrants further investigation.

Newer techniques, such as multi-parameter flow cytometry, time-of-flight mass cytometry (CyTOF) and whole-repertoire $\mathrm{T}$ and $\mathrm{B}$ receptor amplification, can be used to characterize the immunologic cellular makeup of primary and metastatic brain lesions at baseline and changes in circulatory immune cell profile during treatment $(1,72,82,83)$. RNAseq transcriptome profiling of tumor samples can quantify the presence of markers, tumor antigens, and certain genes. The latter has demonstrated utility in predicting survival in neuroblastoma and treatment response in breast cancer (84). Finally, "imaging genomics" or "radiomic" analysis may be a cost-effective and non-invasive strategy to link the radiophenotype of a tumor it its underlying genomic and proteomic characteristics, via the high-throughput extraction and analysis of large amounts of radiographic imaging for distinctive features, which can then be mapped to certain genomic and proteomic patterns such that predictive and prognostic classifications may be made (85-88). Radiomic analysis may be particularly useful to characterize and distinguish radiation necrosis $(\mathrm{RN})$, a potential late adverse effect of high-dose focal irradiation to the brain occurring more frequently in patients receiving ICB (89), from tumor progression or recurrence and the phenomenon of pseudoprogression. Furthermore, this strategy may be used with traditionally measured biomarkers and miRNA profiles to

\section{REFERENCES}

1. Jiang W, Tang C, Chang JY. Radiation with immunotherapy: an emerging combination for cancer treatment. J Radiat Oncol (2015) 4(4):331-8. doi:10.1007/s13566-015-0217-4

2. Korman AJ, Peggs KS, Allison JP. Checkpoint blockade in cancer immunotherapy. Adv Immunol (2006) 90:297-339. doi:10.1016/S0065-2776(06) 90008-X

3. Leach DR, Krummel MF, Allison JP. Enhancement of antitumor immunity by CTLA-4 blockade. Science (1996) 271(5256):1734-6. doi:10.1126/ science.271.5256.1734

4. Brahmer JR, Tykodi SS, Chow LQ, Hwu WJ, Topalian SL, Hwu P, et al. Safety and activity of anti-PD-L1 antibody in patients with advanced cancer. $N$ Engl J Med (2012) 366(26):2455-65. doi:10.1056/NEJMoa1200694

5. Topalian SL, Hodi FS, Brahmer JR, Gettinger SN, Smith DC, McDermott DF, et al. Safety, activity, and immune correlates of anti-PD-1 antibody in cancer. N Engl J Med (2012) 366(26):2443-54. doi:10.1056/NEJMoa1200690

6. Ansell SM, Lesokhin AM, Borrello I, Halwani A, Scott EC, Gutierrez M, et al. PD-1 blockade with nivolumab in relapsed or refractory Hodgkin's lymphoma. N Engl J Med (2015) 372(4):311-9. doi:10.1056/NEJMoa1411087

7. Gettinger SN, Shepherd FA, Antonia SJ, Brahmer JR, Chow LQM, Juergens RA, et al. First-line nivolumab (anti-PD-1; BMS-936558, ONO4538) monotherapy in advanced NSCLC: safety, efficacy, and correlation of outcomes with PD-L1 status. J Clin Oncol (2014) 32(15 Suppl):8024.

8. Motzer RJ, Rini BI, McDermott DF, Redman BG, Kuzel TM, Harrison MR, et al. Nivolumab for metastatic renal cell carcinoma: results of a randomized phase II trial. J Clin Oncol (2015) 33(13):1430-7. doi:10.1200/JCO. 2014.59.0703

9. Tang C, Liao Z, Gomez D, Levy L, Zhuang Y, Gebremichael RA, et al. Lymphopenia association with gross tumor volume and lung V5 and its effects on non-small cell lung cancer patient outcomes. Int J Radiat Oncol Biol Phys (2014) 89(5):1084-91. doi:10.1016/j.ijrobp.2014.04.025 construct multi-dimensional schemes for prediction of response to combining ICB and RT, development of tailored treatment plans, and assessment of adverse effects of such therapy.

\section{CONCLUSION}

A new generation of immunotherapeutics, most prominently the immune checkpoint inhibitors, has ushered in a new era of cancer treatment strategies. Despite the effectiveness of these agents, significant limitations remain. Multiple studies have begun to reveal a synergistic effect between ICB and RT, with numerous clinical trials exploring combinatorial strategies in diverse sites of disease. Primary CNS malignancies, such as glioblastoma, and far more commonly metastatic lesions, carry a grim prognosis and stand to gain much benefit from novel combination approaches utilizing $\mathrm{RT}$ and ICB. Benefits in terms of survival and intracranial control have been shown in the preclinical setting and are now being tested in various trials. However, many important questions remain to be answered. Nevertheless, with improved understanding of how RT interacts with the immune system, combined strategies that utilize RT with ICB may provide a new and effective to treat CNS malignancies.

\section{AUTHOR CONTRIBUTIONS}

NMD performed the literature research. All authors helped to write the manuscript.

10. Postow MA, Callahan MK, Barker CA, Yamada Y, Yuan J, Kitano S, et al. Immunologic correlates of the abscopal effect in a patient with melanoma. N Engl J Med (2012) 366(10):925-31. doi:10.1056/NEJMoa1112824

11. Dewan MZ, Galloway AE, Kawashima N, Dewyngaert JK, Babb JS, Formenti SC, et al. Fractionated but not single-dose radiotherapy induces an immune-mediated abscopal effect when combined with anti-CTLA-4 antibody. Clin Cancer Res (2009) 15(17):5379-88. doi:10.1158/1078-0432. CCR-09-0265

12. Takeshima T, Chamoto K, Wakita D, Ohkuri T, Togashi Y, Shirato H, et al. Local radiation therapy inhibits tumor growth through the generation of tumor-specific CTL: its potentiation by combination with Th1 cell therapy. Cancer Res (2010) 70(7):2697-706. doi:10.1158/0008-5472.CAN09-2982

13. Siva S, Macmanus MP, Martin RF, Martin OA. Abscopal effects of radiation therapy: a clinical review for the radiobiologist. Cancer Lett (2015) 356(1):8290. doi:10.1016/j.canlet.2013.09.018

14. Demaria S, Ng B, Devitt ML, Babb JS, Kawashima N, Liebes L, et al. Ionizing radiation inhibition of distant untreated tumors (abscopal effect) is immune mediated. Int J Radiat Oncol Biol Phys (2004) 58(3):862-70. doi:10.1016/j. ijrobp.2003.09.012

15. Kalbasi A, June $\mathrm{CH}$, Haas N, Vapiwala N. Radiation and immunotherapy: a synergistic combination. J Clin Invest (2013) 123(7):2756-63. doi:10.1172/ JCI69219

16. Formenti SC, Demaria S. Combining radiotherapy and cancer immunotherapy: a paradigm shift. J Natl Cancer Inst (2013) 105(4):256-65. doi:10.1093/ jnci/djs629

17. Vatner RE, Cooper BT, Vanpouille-box C, Demaria S, Formenti SC. Combinations of immunotherapy and radiation in cancer therapy. Front Oncol (2014) 4:325. doi:10.3389/fonc.2014.00325

18. Owonikoko TK, Arbiser J, Zelnak A, Shu HK, Shim H, Robin AM, et al. Current approaches to the treatment of metastatic brain tumours. Nat Rev Clin Oncol (2014) 11(4):203-22. doi:10.1038/nrclinonc.2014.25 
19. Ostrom QT, Gittleman H, Stetson L, Virk SM, Barnholtz-sloan JS. Epidemiology of gliomas. Cancer Treat Res (2015) 163:1-14. doi:10.1007/978-3319-12048-5_1

20. Neagu MR, Reardon DA. An update on the role of immunotherapy and vaccine strategies for primary brain tumors. Curr Treat Options Oncol (2015) 16(11):54. doi:10.1007/s11864-015-0371-3

21. Fecci PE, Heimberger AB, Sampson JH. Immunotherapy for primary brain tumors: no longer a matter of privilege. Clin Cancer Res (2014) 20(22):5620-9. doi:10.1158/1078-0432.CCR-14-0832

22. Carson MJ, Doose JM, Melchior B, Schmid CD, Ploix CC. CNS immune privilege: hiding in plain sight. Immunol Rev (2006) 213:48-65. doi:10.1111/j.1600-065X.2006.00441.x

23. Rivest S. Regulation of innate immune responses in the brain. Nat Rev Immunol (2009) 9(6):429-39. doi:10.1038/nri2565

24. Zeng J, See AP, Phallen J, Jackson CM, Belcaid Z, Ruzevick J, et al. Anti-PD-1 blockade and stereotactic radiation produce long-term survival in mice with intracranial gliomas. Int J Radiat Oncol Biol Phys (2013) 86(2):343-9. doi:10.1016/j.ijrobp.2012.12.025

25. Wainwright DA, Chang AL, Dey M, Balyasnikova IV, Kim CK, Tobias A, et al. Durable therapeutic efficacy utilizing combinatorial blockade against IDO, CTLA-4, and PD-L1 in mice with brain tumors. Clin Cancer Res (2014) 20(20):5290-301. doi:10.1158/1078-0432.CCR-14-0514

26. Fecci PE, Ochiai H, Mitchell DA, Grossi PM, Sweeney AE, Archer GE, et al. Systemic CTLA-4 blockade ameliorates glioma-induced changes to the CD4+ T cell compartment without affecting regulatory T-cell function. Clin Cancer Res (2007) 13(7):2158-67. doi:10.1158/1078-0432.CCR-06-2070

27. Binder DC, Davis AA, Wainwright DA. Immunotherapy for cancer in the central nervous system: current and future directions. Oncoimmunology (2016) 5(2):e1082027. doi:10.1080/2162402X.2015.1082027

28. Kroemer G, Galluzzi L, Kepp O, Zitvogel L. Immunogenic cell death in cancer therapy. Annu Rev Immunol (2013) 31:51-72. doi:10.1146/annurevimmunol-032712-100008

29. Green DR, Ferguson T, Zitvogel L, Kroemer G. Immunogenic and tolerogenic cell death. Nat Rev Immunol (2009) 9(5):353-63. doi:10.1038/nri2545

30. Kepp O, Senovilla L, Vitale I, Vacchelli E, Adjemian S, Agostinis P, et al. Consensus guidelines for the detection of immunogenic cell death. Oncoimmunology (2014) 3(9):e955691. doi:10.4161/21624011.2014.955691

31. Dancea HC, Shareef MM, Ahmed MM. Role of radiation-induced TGFbeta signaling in cancer therapy. Mol Cell Pharmacol (2009) 1(1):44-56. doi:10.4255/mcpharmacol.09.06

32. Tsai CS, Chen FH, Wang CC, Huang HL, Jung SM, Wu CJ, et al. Macrophages from irradiated tumors express higher levels of iNOS, arginase-I and COX-2, and promote tumor growth. Int J Radiat Oncol Biol Phys (2007) 68(2):499-507. doi:10.1016/j.ijrobp.2007.01.041

33. Kachikwu EL, Iwamoto KS, Liao YP, DeMarco JJ, Agazaryan N, Economou JS, et al. Radiation enhances regulatory $\mathrm{T}$ cell representation. Int J Radiat Oncol Biol Phys (2011) 81(4):1128-35. doi:10.1016/j.ijrobp.2010.09.034

34. Ellsworth S, Balmanoukian A, Kos F, Nirschl CJ, Nirschl TR, Grossman SA, et al. Sustained CD4(+) T cell-driven lymphopenia without a compensatory IL-7/IL-15 response among high-grade glioma patients treated with radiation and temozolomide. Oncoimmunology (2014) 3(1):e27357. doi:10.4161/ onci. 27357

35. Obeid M, Tesniere A, Ghiringhelli F, Fimia GM, Apetoh L, Perfettini JL, et al. Calreticulin exposure dictates the immunogenicity of cancer cell death. Nat Med (2007) 13(1):54-61. doi:10.1038/nm1523

36. Vermeer DW, Spanos WC, Vermeer PD, Bruns AM, Lee KM, Lee JH. Radiation-induced loss of cell surface CD47 enhances immune-mediated clearance of human papillomavirus-positive cancer. Int J Cancer (2013) 133(1):120-9. doi:10.1002/ijc.28015

37. Apetoh L, Ghiringhelli F, Tesniere A, Obeid M, Ortiz C, Criollo A, et al. Tolllike receptor 4-dependent contribution of the immune system to anticancer chemotherapy and radiotherapy. Nat Med (2007) 13(9):1050-9. doi:10.1038/ nm1622

38. Reits EA, Hodge JW, Herberts CA, Groothuis TA, Chakraborty M, Wansley EK, et al. Radiation modulates the peptide repertoire, enhances MHC class I expression, and induces successful antitumor immunotherapy. J Exp Med (2006) 203(5):1259-71. doi:10.1084/jem.20052494

39. Burnette B, Weichselbaum RR. Radiation as an immune modulator. Semin Radiat Oncol (2013) 23(4):273-80. doi:10.1016/j.semradonc.2013.05.009
40. Twyman-Saint Victor C, Rech AJ, Maity A, Rengan R, Pauken KE, Stelekati E, et al. Radiation and dual checkpoint blockade activate non-redundant immune mechanisms in cancer. Nature (2015) 520(7547):373-7. doi:10.1038/ nature 14292

41. Louveau A, Smirnov I, Keyes TJ, Eccles JD, Rouhani SJ, Peske JD, et al. Structural and functional features of central nervous system lymphatic vessels. Nature (2015) 523(7560):337-41. doi:10.1038/nature14432

42. Parsa AT, Waldron JS, Panner A, Crane CA, Parney IF, Barry JJ, et al. Loss of tumor suppressor PTEN function increases B7-H1 expression and immunoresistance in glioma. Nat Med (2007) 13(1):84-8. doi:10.1038/nm1517

43. Bloch O, Crane CA, Kaur R, Safaee M, Rutkowski MJ, Parsa AT. Gliomas promote immunosuppression through induction of $\mathrm{B} 7-\mathrm{H} 1$ expression in tumor-associated macrophages. Clin Cancer Res (2013) 19(12):3165-75. doi:10.1158/1078-0432.CCR-12-3314

44. Taube JM, Anders RA, Young GD, Xu H, Sharma R, McMiller TL, et al. Colocalization of inflammatory response with $\mathrm{B} 7 \mathrm{-h} 1$ expression in human melanocytic lesions supports an adaptive resistance mechanism of immune escape. Sci Transl Med (2012) 4(127):127ra37. doi:10.1126/ scitranslmed.3003689

45. Berghoff AS, Ricken G, Widhalm G, Rajky O, Hainfellner JA, Birner P, et al. PD1 (CD279) and PD-L1 (CD274, B7H1) expression in primary central nervous system lymphomas (PCNSL). Clin Neuropathol (2014) 33(1):42-9. doi:10.5414/NP300698

46. Berghoff AS, Ricken G, Widhalm G, Rajky O, Dieckmann K, Birner P, et al. Tumour-infiltrating lymphocytes and expression of programmed death ligand 1 (PD-L1) in melanoma brain metastases. Histopathology (2015) 66(2):289-99. doi:10.1111/his.12537

47. Belcaid Z, Phallen JA, Zeng J, See AP, Mathios D, Gottschalk C, et al. Focal radiation therapy combined with 4-1BB activation and CTLA-4 blockade yields long-term survival and a protective antigen-specific memory response in a murine glioma model. PLoS One (2014) 9(7):e101764. doi:10.1371/ journal.pone.0101764

48. Deng L, Liang H, Burnette B, Weicheslbaum RR, Fu YX. Radiation and anti$\mathrm{PD}-\mathrm{L} 1$ antibody combinatorial therapy induces T cell-mediated depletion of myeloid-derived suppressor cells and tumor regression. Oncoimmunology (2014) 3:e28499. doi:10.4161/onci.28499

49. Smilowitz HM, Micca PL, Sasso D, Wu Q, Dyment N, Xue C, et al. Increasing radiation dose improves immunotherapy outcome and prolongation of tumor dormancy in a subgroup of mice treated for advanced intracerebral melanoma. Cancer Immunol Immunother (2016) 65(2):127-39. doi:10.1007/ s00262-015-1772-7

50. Van vulpen M, Kal HB, Taphoorn MJ, El-sharouni SY. Changes in blood-brain barrier permeability induced by radiotherapy: implications for timing of chemotherapy? (Review). Oncol Rep (2002) 9(4):683-8.

51. Stamell EF, Wolchok JD, Gnjatic S, Lee NY, Brownell I. The abscopal effect associated with a systemic anti-melanoma immune response. Int J Radiat Oncol Biol Phys (2013) 85(2):293-5. doi:10.1016/j.ijrobp.2012.03.017

52. Hiniker SM, Chen DS, Reddy S, Chang DT, Jones JC, Mollick JA, et al. A systemic complete response of metastatic melanoma to local radiation and immunotherapy. Transl Oncol (2012) 5(6):404-7. doi:10.1593/tlo.12280

53. Golden EB, Demaria S, Schiff PB, Chachoua A, Formenti SC. An abscopal response to radiation and ipilimumab in a patient with metastatic non-small cell lung cancer. Cancer Immunol Res (2013) 1(6):365-72. doi:10.1158/23266066.CIR-13-0115

54. Kwon ED, Drake CG, Scher HI, Fizazi K, Bossi A, van den Eertwegh AJ, et al. Ipilimumab versus placebo after radiotherapy in patients with metastatic castration-resistant prostate cancer that had progressed after docetaxel chemotherapy (CA184-043): a multicentre, randomised, double-blind, phase 3 trial. Lancet Oncol (2014) 15(7):700-12. doi:10.1016/S1470-2045(14)70189-5

55. Slovin SF, Higano CS, Hamid O, Tejwani S, Harzstark A, Alumkal JJ, et al. Ipilimumab alone or in combination with radiotherapy in metastatic castration-resistant prostate cancer: results from an open-label, multicenter phase I/ II study. Ann Oncol (2013) 24(7):1813-21. doi:10.1093/annonc/mdt107

56. Gerritsen W, Kwon E, Fizazi K, Bossi A, Van Den Eertwegh A, Logothetis C, et al. CA184-043: a randomized, multicenter, double-blind phase 3 trial comparing overall survival (OS) in patients (PTS) with post-docetaxel castration-resistant prostate cancer (CRPC) and bone metastases treated with ipilimumab (IPI) versus placebo (PBO), each following single-dose radiotherapy (RT). European Cancer Congress (2013) Abstract 2850. 
57. Patel KR, Lawson DH, Kudchadkar RR, Carthon BC, Oliver DE, OkwanDuodu $\mathrm{D}$, et al. Two heads better than one? Ipilimumab immunotherapy and radiation therapy for melanoma brain metastases. Neuro Oncol (2015) 17(10):1312-21. doi:10.1093/neuonc/nov093

58. Knisely JP, Yu JB, Flanigan J, Sznol M, Kluger HM, Chiang VL. Radiosurgery for melanoma brain metastases in the ipilimumab era and the possibility of longer survival. J Neurosurg (2012) 117(2):227-33. doi:10.3171/2012.5. JNS111929

59. Silk AW, Bassetti MF, West BT, Tsien CI, Lao CD. Ipilimumab and radiation therapy for melanoma brain metastases. Cancer Med (2013) 2(6):899-906. doi:10.1002/cam4.140

60. Kiess AP, Wolchok JD, Barker CA, Postow MA, Tabar V, Huse JT, et al. Stereotactic radiosurgery for melanoma brain metastases in patients receiving ipilimumab: safety profile and efficacy of combined treatment. Int J Radiat Oncol Biol Phys (2015) 92(2):368-75. doi:10.1016/j.ijrobp.2015.01.004

61. Weber JS, Amin A, Minor D, Siegel J, Berman D, O’day SJ. Safety and clinical activity of ipilimumab in melanoma patients with brain metastases: retrospective analysis of data from a phase 2 trial. Melanoma Res (2011) 21(6):530-4. doi:10.1097/CMR.0b013e32834d3d88

62. Chow KK, Hara W, Lim M, Li G. Combining immunotherapy with radiation for the treatment of glioblastoma. J Neurooncol (2015) 123(3):459-64. doi:10.1007/s11060-015-1762-9

63. Wen PY, Reardon DA, Phuphanich S, Aiken R, Landolfi JC, Curry WT, et al. A randomized, double-blind, placebo-controlled phase 2 trial of dendritic cell (DC) vaccination with ICT-107 in newly diagnosed glioblastoma (GBM) patients. ASCO Annual Meeting Proceedings. (Vol. 32). Chicago, IL: J Clin Oncol (Meeting Abstracts) (2014). 2005 p. May 20.

64. El andaloussi A, Lesniak MS. An increase in CD4+CD25+FOXP3+ regulatory $\mathrm{T}$ cells in tumor-infiltrating lymphocytes of human glioblastoma multiforme. Neuro Oncol (2006) 8(3):234-43. doi:10.1215/15228517-2006-006

65. Crane CA, Ahn BJ, Han SJ, Parsa AT. Soluble factors secreted by glioblastoma cell lines facilitate recruitment, survival, and expansion of regulatory T cells: implications for immunotherapy. Neuro Oncol (2012) 14(5):584-95. doi:10.1093/neuonc/nos014

66. Jacobs JF, Idema AJ, Bol KF, Grotenhuis JA, de Vries IJ, Wesseling P, et al. Prognostic significance and mechanism of Treg infiltration in human brain tumors. J Neuroimmunol (2010) 225(1-2):195-9. doi:10.1016/ j.jneuroim.2010.05.020

67. Wei J, Wu A, Kong LY, Wang Y, Fuller G, Fokt I, et al. Hypoxia potentiates glioma-mediated immunosuppression. PLoS One (2011) 6(1):e16195. doi:10.1371/journal.pone.0016195

68. Berghoff AS, Kiesel B, Widhalm G, Rajky O, Ricken G, Wöhrer A, et al. Programmed death ligand 1 expression and tumor-infiltrating lymphocytes in glioblastoma. Neuro Oncol (2015) 17(8):1064-75. doi:10.1093/neuonc/ nou307

69. Snyder A, Makarov V, Merghoub T, Yuan J, Zaretsky JM, Desrichard A, et al. Genetic basis for clinical response to CTLA-4 blockade in melanoma. N Engl J Med (2014) 371(23):2189-99. doi:10.1056/NEJMoa1406498

70. Rizvi NA, Hellmann MD, Snyder A, Kvistborg P, Makarov V, Havel JJ, et al. Cancer immunology. Mutational landscape determines sensitivity to PD-1 blockade in non-small cell lung cancer. Science (2015) 348(6230):124-8. doi:10.1126/science.aaa1348

71. Preusser M, Lim M, Hafler DA, Reardon DA, Sampson JH. Prospects of immune checkpoint modulators in the treatment of glioblastoma. Nat Rev Neurol (2015) 11(9):504-14. doi:10.1038/nrneurol.2015.139

72. Reardon DA, Schuster JM, Tran DD, Fink KL, Nabors LB, Li G, et al. 107 ReACT: overall survival from a randomized phase II study of rindopepimut (CDX-110) plus bevacizumab in relapsed glioblastoma. Neurosurgery (2015) 62:198-9. doi:10.1227/01.neu.0000467069.86811.3f

73. Sims JS, Ung TH, Neira JA, Canoll P, Bruce JN. Biomarkers for glioma immunotherapy: the next generation. J Neurooncol (2015) 123(3):359-72. doi:10.1007/s11060-015-1746-9

74. Garzon R, Marcucci G, Croce CM. Targeting microRNAs in cancer: rationale, strategies and challenges. Nat Rev Drug Discov (2010) 9(10):775-89. doi:10.1038/nrd3179
75. Qu S, Guan J, Liu Y. Identification of microRNAs as novel biomarkers for glioma detection: a meta-analysis based on 11 articles. J Neurol Sci (2015) 348(1-2):181-7. doi:10.1016/j.jns.2014.11.036

76. Roth P, Wischhusen J, Happold C, Chandran PA, Hofer S, Eisele G, et al. A specific miRNA signature in the peripheral blood of glioblastoma patients. J Neurochem (2011) 118(3):449-57. doi:10.1111/j.1471-4159.2011.07307.x

77. Manterola L, Guruceaga E, Gállego Pérez-Larraya J, González-Huarriz M, Jauregui P, Tejada S, et al. A small noncoding RNA signature found in exosomes of GBM patient serum as a diagnostic tool. Neuro Oncol (2014) 16(4):520-7. doi:10.1093/neuonc/not218

78. Teplyuk NM, Mollenhauer B, Gabriely G, Giese A, Kim E, Smolsky M, et al. MicroRNAs in cerebrospinal fluid identify glioblastoma and metastatic brain cancers and reflect disease activity. Neuro Oncol (2012) 14(6):689-700. doi:10.1093/neuonc/nos074

79. Thorsen SB, Obad S, Jensen NF, Stenvang J, Kauppinen S. The therapeutic potential of microRNAs in cancer. Cancer J (2012) 18(3):275-84. doi:10.1097/ PPO.0b013e318258b5d6

80. Würdinger T, Tannous BA, Saydam O, Skog J, Grau S, Soutschek J, et al. miR296 regulates growth factor receptor overexpression in angiogenic endothelial cells. Cancer Cell (2008) 14(5):382-93. doi:10.1016/j.ccr.2008.10.005

81. Wei J, Nduom EK, Kong LY, et al. MiR-138 exerts anti-glioma efficacy by targeting immune checkpoints. Neuro Oncol (2016) 18(5):639-48. doi:10.1093/ neuonc/nov292

82. Gustafson MP, Lin Y, LaPlant B, Liwski CJ, Maas ML, League SC, et al. Immune monitoring using the predictive power of immune profiles. J Immunother Cancer (2013) 1:7. doi:10.1186/2051-1426-1-7

83. Tumeh PC, Harview CL, Yearley JH, Shintaku IP, Taylor EJ, Robert L, et al. PD-1 blockade induces responses by inhibiting adaptive immune resistance. Nature (2014) 515(7528):568-71. doi:10.1038/nature13954

84. Nielsen T, Wallden B, Schaper C, Ferree S, Liu S, Gao D, et al. Analytical validation of the PAM50-based prosigna breast cancer prognostic gene signature assay and nCounter analysis system using formalin-fixed paraffin-embedded breast tumor specimens. BMC Cancer (2014) 14:177. doi:10.1186/1471-2407-14-177

85. Kumar V, Gu Y, Basu S, Berglund A, Eschrich SA, Schabath MB, et al. Radiomics: the process and the challenges. Magn Reson Imaging (2012) 30(9):1234-48. doi:10.1016/j.mri.2012.06.010

86. Lambin P, Rios-Velazquez E, Leijenaar R, Carvalho S, van Stiphout RG, Granton P, et al. Radiomics: extracting more information from medical images using advanced feature analysis. Eur J Cancer (2012) 48(4):441-6. doi:10.1016/j.ejca.2011.11.036

87. Zinn PO, Mahajan B, Sathyan P, Singh SK, Majumder S, Jolesz FA, et al. Radiogenomic mapping of edema/cellular invasion MRI-phenotypes in glioblastoma multiforme. PLoS One (2011) 6(10):e25451. doi:10.1371/journal. pone. 0025451

88. Zhou M, Hall L, Goldgof D, Russo R, Balagurunathan Y, Gillies R, et al. Radiologically defined ecological dynamics and clinical outcomes in glioblastoma multiforme: preliminary results. Transl Oncol (2014) 7(1):5-13. doi:10.1593/tlo.13730

89. Colaco RJ, Martin P, Kluger HM, Yu JB, Chiang VL. Does immunotherapy increase the rate of radiation necrosis after radiosurgical treatment of brain metastases? J Neurosurg (2016) 125(1):17-23. doi:10.3171/2015.6.JNS142763

Conflict of Interest Statement: JLi received research funding from BMS to support the research expenses of a phase I/II clinical trial with immunotherapy. The rest of the authors report no conflicts of interest.

Copyright $\odot 2016$ D'Souza, Fang, Logan, Yang, Jiang and Li. This is an open-access article distributed under the terms of the Creative Commons Attribution License (CC BY). The use, distribution or reproduction in other forums is permitted, provided the original author(s) or licensor are credited and that the original publication in this journal is cited, in accordance with accepted academic practice. No use, distribution or reproduction is permitted which does not comply with these terms. 